\title{
IT PROJECT MANAGEMENT: CLASS PROJECT OF A POINT OF SALE (POS) SYSTEM IMPLEMENTATION IN A RESTAURANT
}

\author{
Amber Gillum, University of Houston - Clear Lake, gilluma7531@uhcl.edu \\ Mohammad A. Rob, University of Houston - Clear Lake, rob@uhcl.edu
}

\begin{abstract}
One of the best ways in which students acquire knowledge in an IT project management course is through the application of concepts taught in the course and the planning of implementation of projects with bases in the realworld [4]. These capstone projects enable the learner to gain real world experience in a relatively safe academic environment. This paper focuses on the implementation of a POS system in the hospitality industry-specifically a table service restaurant. The course's design and methodology and case concept are discussed. This case has application for instructional use in IT project management as well as an overview of the potential risks and benefits of the approach used in managing the project's implementation.
\end{abstract}

Key Words: Point of Sale (POS), Wireless, Touch screen, Project Management, Case.

\section{INTRODUCTION}

Point of sale (POS) systems, sometimes referred to as Point of Purchase systems refer to the location of a transaction also known as a checkout. These systems include cash registers, handheld devices, special terminals, optical scanners and magnetic card readers. POS systems are widely used in the retail and hospitality industry. The use of POS systems in table service restaurants in particular has revolutionized the business by allowing wait staff to not only function in their roles as order takers and servers, but also as salespersons in that they may utilize touch screens on both registers and wireless devices [1] to track customer preferences, make suggestions to customers based on past order history [2], and monitor a restaurant's inventory thereby mitigating the risk of theft, waste, and other problems that are common to the food service industry [3]. POS systems further serve to automate core business functions such as labor management and the generation of financial reports. As one's economy becomes increasingly global, the necessity of POS systems' functionality in accommodating varying languages increases in importance. Given the detailed planning necessary for the effective implementation of a POS system, high quality IT project management is required at the outset. Our case study focuses on the project management of the implementation of a multi-station POS system within the hospitality industry specifically a Japanese table service restaurant.

\section{COURSE DESIGN AND METHODOLOGY}

\section{Course Purpose}

The purpose of the course is to provide students with an essential knowledge of information systems project management including a review of project management techniques with regards to application to software project management and development plans. Students are introduced to the tools employed in cost estimation/budgeting, defining deliverables, assigning tasks, and tracking milestones. Furthermore, students are prepared for careers in project management by the implementation of real-world project scenarios. Finally, content specific to the successful completion of the PMP exam is covered in the one-semester course.

\section{Key Course Components}

The IT project management course for which this project was developed is a graduate-level course in management and information sciences that is typically taken by students nearing the end of their studies. Students are required to work in small groups of 4-5 participants and to choose an industry of focus for their project-such as retail, 
hospitality, transportation, or oil and gas field services to name a few. Each group consists of two subgroups: one subgroup for management and another for execution. Students in the management subgroup are given the option of designating one of the group members as the project manager rotating this role over the course of the semester. An additional designation is the systems analyst/assistant project manager. The execution group is responsible for coding, analysis, and testing. Students are further required to execute the project planning utilizing the PMBOK systems-based methodology of IT project management organized as five project management process groups: 1) initiation, 2) planning and design, 3) execution, 4) monitoring and controlling, and 5) closing. Required software for the course is Microsoft Project Management. Students utilize a number of resources to complete the course requirements including class lectures, textbooks, and online resources. The course requires group project work, group presentations and documentation, two research papers, tests, and group discussions. The textbook required for the course is Information Technology Project Management, Sixth Edition [5].

\section{CASE CONCEPT OF A JAPANESE RESTAURANT}

\section{Business Scenario}

Hakubi Japanese Brasserie is a hypothetical Japanese-themed table service restaurant which aims to set the standard for contemporary Japanese dining as a modern version of a traditional Japanese pub. The restaurant opened in a strip mall in 2009 with ten tables and a modest-sized wait staff. The owners purchased one small business electronic

LEVEL 2 DIAGRAM - RECEIVE AND TRANSFORM ORDER

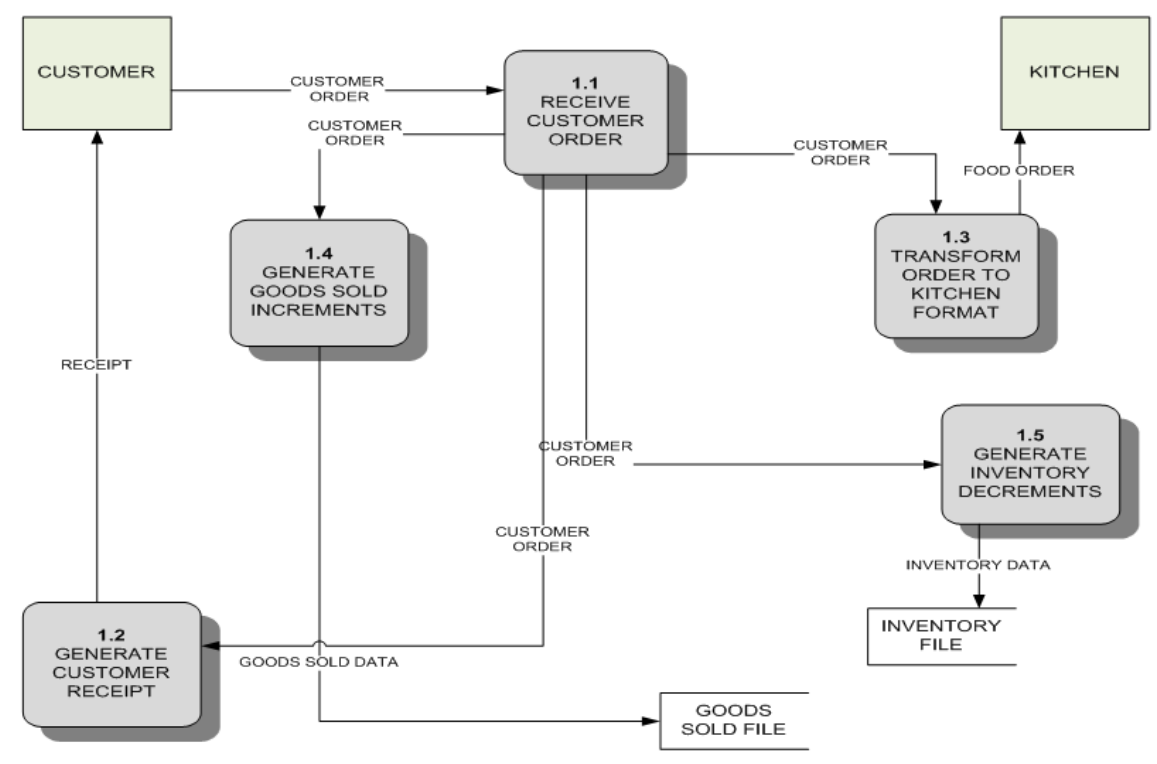

Figure 1 - Hakubi Japanese Brasserie POS System Context Diagram

cash register that is relatively simple to use in managing sales. Within two years, the restaurant expanded its operations by 40 percent and take-out orders increased by 45 percent.

\section{Business Need}

In consultation with the project contractor, the restaurant's owners indicated that they require much more than a standard cash register and money storage. A survey of their operations and subsequent consultations indicated that they need a solution that will accommodate the changing needs of their growing business. Additionally, the restaurant staff spends in the range of four to six hours weekly taking phone orders. The staff wants to receive 
orders securely in real time. During peak dining hours, it is not always possible for staff to stop and answer the phone whereas online ordering is potentially always available.

\section{Proposed Solution: POS}

Hakubi Japanese Brasserie needs a fully integrated Point of Sale (POS) System to help the restaurant increase efficiency and help eliminate waste in physical and human resources. Tensai Solutions has been engaged by the client to develop its POS system. Tensai Solutions will customize a web-based multi-station Point of Sales System with features such as touch screens, automatic ordering and high speed credit card readers. The system will automate core business functions by tracking inventory, ordering supplies, managing labor, and generating financial reports. The POS system must comprise of a number of added functionalities not typically found in these systems (e.g. customer order history and a Japanese language option) that improve the user and customer experience and makes the system more robust. More importantly, the system will need scalability which expands to accommodate both present and future business requirements. Figure 1 details the client's vision of how the POS system will allow them to receive and transform orders in a timely manner as well as track inventory and customer preferences represented as a data flow diagram (DFD). Additionally, Hakubi Japanese Brasserie requires a web-based business solution designed to assist personnel in retrieving online orders with ease. The website will be designed to interface with the POS system. The product will be built on an Oracle database with a GUI interface. To limit the project's cost, the client will have its network installed prior to the beginning of Tensai Solutions' contractual work period.

\section{Expected Challenges}

There are several challenges to project implementation that we have foreseen in the planning phases of the project. One is that the system must be capable of interfacing with Japanese language systems. This is an important challenge to surmount given the many differences in meaning and structures between English and Japanese. Extensive interface testing is required at each phase of project build-out. See Figure 2 which provides examples of the English and Japanese language reporting screens. Another important consideration is that wireless devices in the POS system must have access to the website at all times in order to ensure fast and consistent order processing. Although there was a stated preference for an Oracle database amongst the team members, any database could be used. In order to ensure timely customer service, the system will cease taking orders thirty minutes prior to closing.

\section{System Benefits and Limitations}

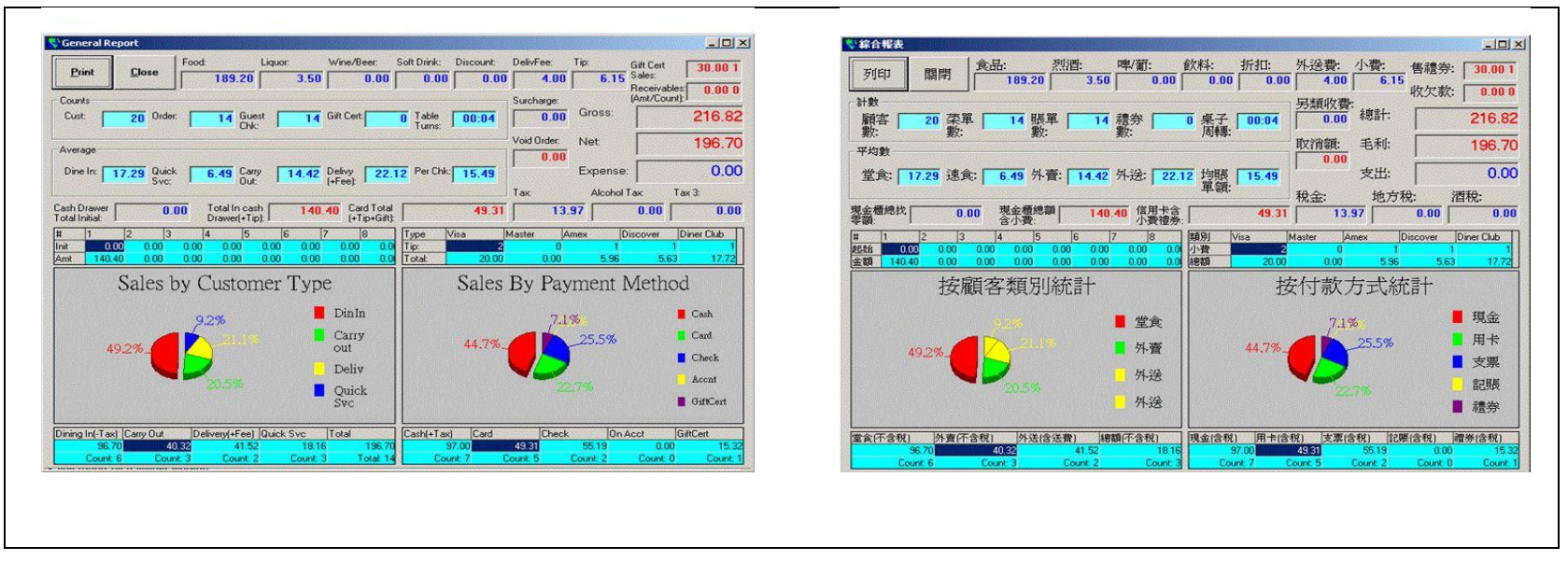

Figure 2-Example of English and Japanese Financial Reporting Screens

The POS system implemented at Hakubi Japanese Brasserie presents several key benefits and limitations. A costbenefit analysis reveals that the benefits integrated into the system's design cumulatively outweigh any projected 
limitations. Using net-present value and ROI (total discounted benefits - total discounted costs)/total discounted costs) analyses, payback occurs in Year 4. A separate analysis of employees' latent potential also reveals that the POS system may maximize the time wait staff and other restaurant personnel spend doing their jobs. For example, prior to system implementation, wait staff were required to travel from customer tables to a cash register terminal in order to process credit cards. During busy periods such as the lunch hour and dinner rush, wait staff might have even spent time waiting in line to use the cash register. There was also greater potential for confusion when a party presented multiple credit cards for payment of orders for one table. One benefit of the use of wireless devices in the POS is that this development allows servers to process orders at the customer's table and accurately process any instructions for multiple credit card payments. Because servers' devices are in themselves terminals, there is no need to stand in line to use a register thereby speeding order processing and table turnover. The use of wireless devices in the POS produces an environmental benefit as well by reducing the paper trail and the carbon footprint

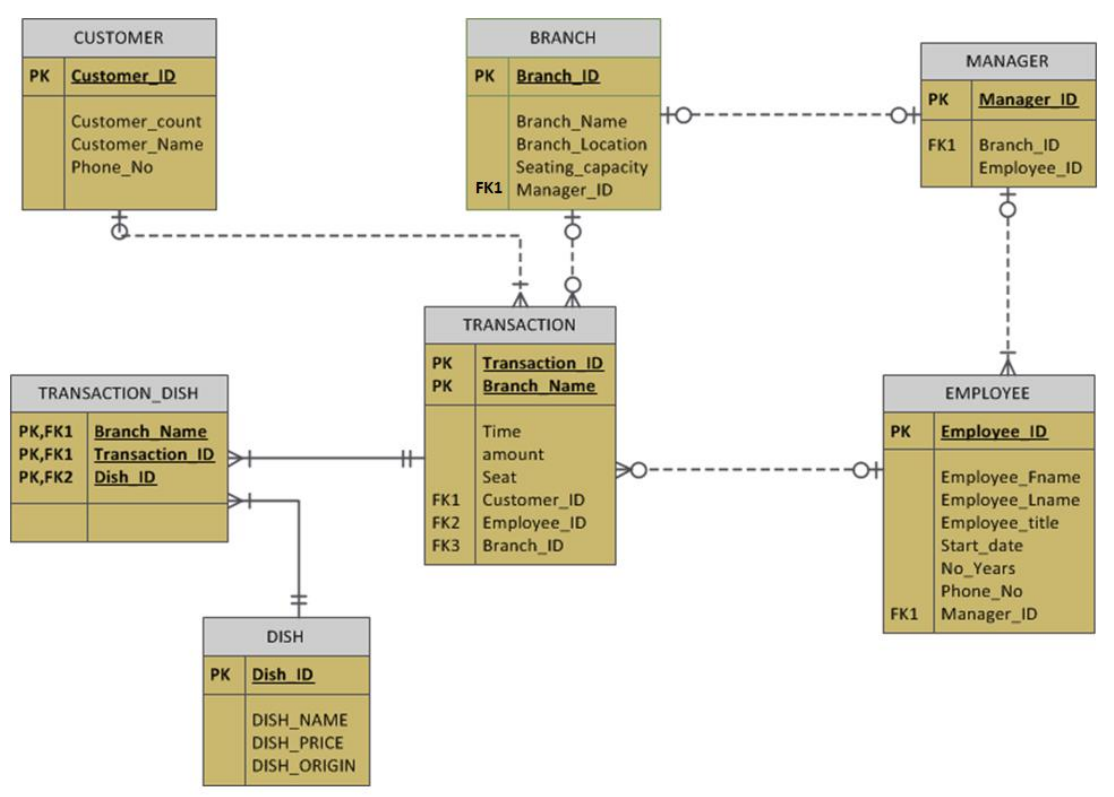

Figure 3-ER Diagram

associated with cash register terminals. These devices provide ready tracking of customer information that can be used for promotional materials through emails and texts as well as kiosks thereby reducing the production costs associated with paper mailings. Limitations present in the system are the need for the system to have internet access at all times. The need for continuous internet access runs the risk of critical business interruptions should a server go down or should internet access be otherwise interrupted. The Wi-Fi standard represents a security risk as the potential for security breaches is increased through the use of wireless devices. For this reason, security for the network was planned using the same features found in a wired network. The increased security risk of Wi-Fi also necessitates the need for enhanced security measures and data encryption using an https protocol. In addition the system will not cache or save usernames or passwords on the magnetic card readers. Adequate firewalls, virus protection, and security layers are included in the system as a matter of course. Other security features include automatic log-out when a session is idle for a specified period of time, limited log-in attempts with a block after a specified number of attempts, and tracking of individual user's transactions with reports automatically sent to the restaurant's management and/or other designated persons. There is also a greater cost associated with backup storage to the system than the costs associated with maintaining on-site storage alone. There is also a potential for customers to fail to adapt to on-line ordering and/or tableside checkout. 
Volume XII, No. 2, pp. 67-73-, 2011

\section{Testing and Database Plan}

A detailed testing plan was designed prior to POS implementation. The testing plan included graphical user interface testing with regards to scalability to account for differences in finger size and shape for wireless devices and touch screens, and comfort in the use of reading screens used in the dual-language feature. Cashier activity testing was also planned. This testing includes scenarios of customer transactions such as ability to read a card, specifically by card type (Magnetic Stripe, CAV, etc), correct entry of items and deletion of items, the use of store value cards for discounts as well as gift card transactions, and support of scanners, local and remote printers. The plan also includes noncustomer transactions such as cash drawer loans, petty cash, server totals, receipts, and closings. Load testing of the system is scheduled to occur with back-ups in place in the event of system failure. Platform (specifically Windows ${ }^{\circledR} \mathrm{CE}$ ), performance, and connectivity tests were also included as part of the testing plan.

The entity-relationship (ER) Diagram presented in Figure 3 provides the conceptual representation of the data elements in the POS system. In Figure 3, one can clearly see the interdependency built into the system as well as the attributes of each. The three external entities are Customer, Kitchen, and Manager with varying numbers of sub processes in Levels 1 and 2.

\section{CONCLUSION AND DISCUSSION}

In keeping with the process of continuous improvement, lessons learned from the experience of this project implementation have been documented in order to enhance latter stages of the project as well as improve future project planning. In this section, I discuss 1) the strategies, events, and processes that led to the successful project implementation as well as 2) areas for potential improvement. Finally, I address solutions to the identified shortcomings in the project.

\section{Strategies, Events, Processes Leading to Successful Implementation}

The project was successful in the following areas: 1) managing stakeholder expectations 2) understanding of successful project components, 3) leveraging the strengths of individual team members, and 4) showing appreciation for team member efforts:

- Managing stakeholder expectations-Throughout the course of the project, project manager actively communicated with project stakeholders which included agency heads, CIOs, and the project's representatives. This communication included soliciting feedback from clients through the use of a client feedback form. Weekly and bi-weekly status reports were also submitted to the project's sponsor. Client feedback was also solicited regularly including an on-line feedback form (See Figure 4)

- Understanding of successful project components-Analysis of the project's adherence to the Gantt chart in terms of accountability and implementations testing revealed what elements of the project were working and which needed improvement. These successful elements included clear and consistent communications with the project's sponsor and other major stakeholders. The tracking and prioritization of project-related issues was also a critical component of the project's ultimate success in on-time delivery of a quality product within projected cost constraints.

- Leveraging the strengths of individual team members- Early on in the project's development an analysis of each team member's strengths and limitations was made in order to assign tasks and develop team members in some of their areas of concern. The team member who had the most experience in project management was selected as the project's manager. Other team members who indicated technical expertise were assigned the roles of database developer, website and testing engineer, system architect, and VB developer. The project's business analyst had a technical background.

- Showing appreciation for team member efforts-Team members were applauded for their efforts in each team meeting and significant achievements were highlighted in conversations and written communications. 
Volume XII, No. 2, pp. 67-73-, 2011

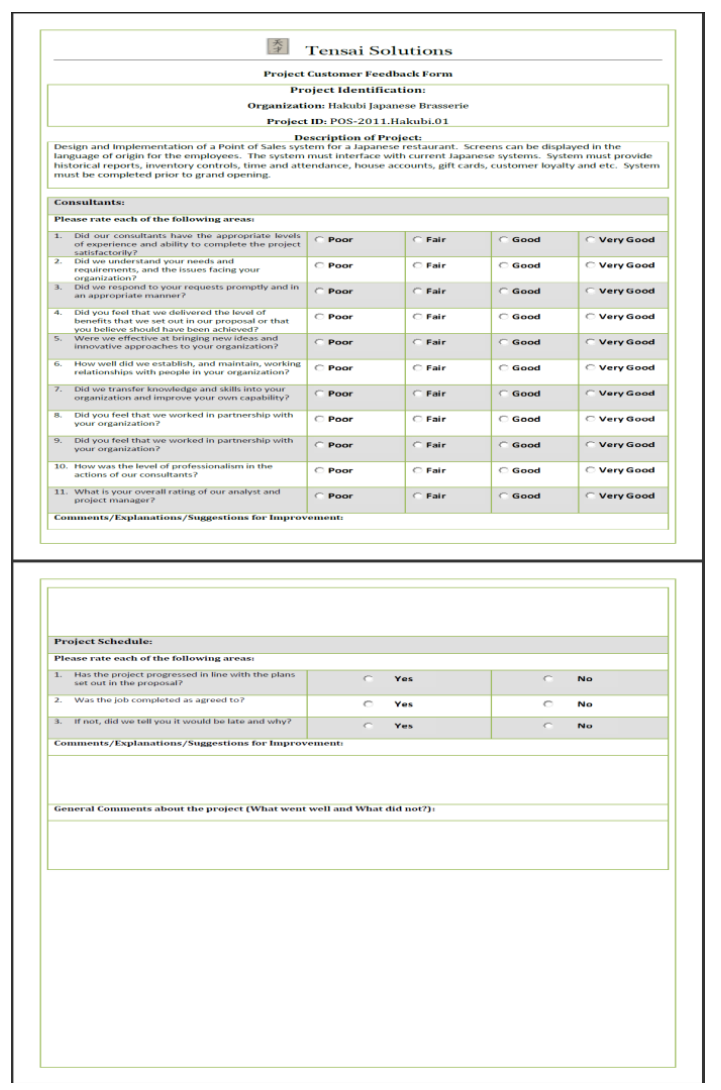

Figure 4-Client Feedback Form

\section{Areas for Potential Improvement}

Several areas were identified in which the project could be improved. One cause for concern is that the time allotted for project implementation was short indicating the need for a longer time horizon. Many items were adjusted in the scope of the project given the limited time period for implementation and testing. However it is noted that this is often the case in the real world as a project's scope may be altered with little notice to the team and/or other factors may cause the project timeline to be lengthened due to hindrances to implementation and testing. Hence PMBOK principles emphasize "Rolling Wave Planning" and "Progressive Elaboration." Rolling Wave Planning is an ongoing and iterative planning process. According to Progressive Elaboration, the project should be developed in discrete steps. In the same vein, timeliness in completing project deliverables continued to be an area of concern with significant improvements seen over the course of the project's duration In addition as is often the case with team work, there is the perception that not all members contribute equally - whether real or imagined this perception presents difficulties in managing expectations and maintaining group morale. Given that in the academic environment, students are incentivized by grades, a proposed solution to this problem of lack of equal effort is to give both group and individual grades on project components. Finally, more frequent and clear communications among team members was also identified as an area for concern and measures were taken to enhance this during the duration of the implementation. Face time was added to overcome busy schedules and team members were encouraged to speak with the PM whenever anything was unclear and updated documents were then promptly distributed to all team members. 
Volume XII, No. 2, pp. 67-73-, 2011

At the project's close, the owner of Hakubi Japanese Brasserie expressed pleasure with the successful implementation of their POS system within their restaurant. The project was implemented in a timely manner within the projected budget and with no cost over-runs. Lessons learned from the implementation include the need for more time in the project's testing phase, greater utilization of all team members, and tighter adherence to the project's scope. The use of the approach described as an instructional tool in project management is easily replicated and has general appeal for students even in the beginning of their graduate careers.

\section{REFERENCES}

1. Fitzgerald, M. (2008, August 24). Turning Point For Touch Screens. New York Times. p. 3.

2. Kashima, T., Matsumoto, S., \& Ishii, H. (2010). Feasibility of Integrated Menu Recommendation and SelfOrder System for Small-Scale Restaurants. AIP Conference Proceedings, 1285(1), 132-144.

3. Manion, C., \& DeMicco, F. J. (2004). Handheld Wireless Point of Sale Systems in the Restaurant Industry. Journal of Foodservice Business Research, 7(2), 103-111.

4. Phillips, C. (2010). Students' Research Experiences During Consulting Projects: Three Themes Emerging from Case Studies. Behavioral \& Social Sciences Librarian, 29(2), 91-108.

5. Schawlbe, K. (2009) Information Technology Project Management, Sixth Edition, Course Technology/Cengage 